\title{
Clinical outcomes of surgical embolectomy versus catheter-directed thrombolysis for acute limb ischemia: a nationwide cohort study
}

\author{
Po-Kai Yang ${ }^{1} \cdot$ Chien-Chou Su${ }^{2} \cdot$ Chih-Hsin $\mathrm{Hsu}^{3}$ iD
}

Accepted: 17 July 2021 / Published online: 3 August 2021

(c) The Author(s) 2021

\begin{abstract}
In Taiwan, the outcomes of acute limb ischemia have yet to be investigated in a standardized manner. In this study, we compared the safety, feasibility and outcomes of acute limb ischemia after surgical embolectomy or catheter-directed therapy in Taiwan. This study used data collected from the Taiwan's National Health Insurance Database (NHID) and Cause of Death Data between the years 2000 and 2015. The rate ratio of all-cause in-hospital mortality and risk of amputation during the same period of hospital stay were estimated using Generalized linear models (GLM). There was no significant difference in mortality risk between CDT and surgical intervention (9.5\% vs. $10.68 \%$, adjusted rate ratio (95\% CI): regression 1.0 [0.79-1.27], PS matching 0.92 [0.69-1.23]). The risk of amputation was also comparable between the two groups. (13.59\% vs. $14.81 \%$, adjusted rate ratio (95\% CI): regression 0.84 [0.68-1.02], PS matching 0.92 [0.72-1.17]). Age $(p<0.001)$ and liver disease $(p=0.01)$ were associated with higher mortality risks. Heart failure $(p=0.03)$ and chronic or end-stage renal disease $(p=0.03)$ were associated with higher amputation risks. Prior antithrombotic agent use $(p=0.03)$ was associated with a reduced risk of amputation. Both surgical intervention and CDT are effective and feasible procedures for patients with ALI in Taiwan.
\end{abstract}

Keywords Acute limb ischemia $\cdot$ Embolectomy $\cdot$ Endovascular therapy $\cdot$ Thrombolysis

\section{Highlights}

- There are limited data for comparison between catheterdirected thrombolysis and surgical intervention for acute limb ischemia in Asian population.

- There was no significant difference observed in the rates of mortality or rates of amputation between two treatment groups.

Chih-Hsin Hsu

chihhsinhsu@gmail.com

1 Division of Cardiology, Department of Internal Medicine, National Cheng Kung University Hospital, Dou-Liou Branch, College of Medicine, National Cheng Kung University, Yunlin, Taiwan

2 Department of Pharmacy, National Cheng Kung University Hospital, College of Medicine, National Cheng Kung University, Tainan, Taiwan

3 Division of Critical Care, Department of Internal Medicine, National Cheng Kung University Hospital, College of Medicine, National Cheng Kung University, 138 Sheng Li Road, Tainan, Taiwan
- Age and liver disease were associated with high mortality risks. Heart failure and chronic renal disease were associated higher amputation risks.

\section{Introduction}

Acute limb ischemia (ALI) is a vascular emergency where the arterial blood supply to one or more extremities is acutely reduced in a manner that threatens the viability of a limb [1]. Without timely revascularization, the rate of limb loss can be as high as $40 \%$ with a mortality rate of $15-20 \%$ [1].

Revascularization is traditionally achieved through surgical thrombectomy or bypass surgery. With the advancement of catheter-based technologies, Catheter-directed thrombolysis (CDT) became a viable option for revascularization [2]. In Taiwan, the outcomes of acute limb ischemia has yet to be investigated in a standardized manner. In this study, we compared the safety, feasibility and outcomes of acute limb ischemia after surgical embolectomy or catheter-directed therapy in Taiwan. 


\section{Materials and methods}

\section{Data source}

This study used data collected from the National Health Insurance Database (NHID) and Cause of Death Data between the years 2000 and 2015. The Ministry of Health and Welfare provided the two databases and the databases are maintained by the Health and Welfare Data Science Center (HWDC) in Taipei City. The NHID collects its data from the claims made to Taiwan's National Health Insurance program, a national health insurance program that covers close to $99 \%$ of the population in Taiwan. The NHID includes a registry for beneficiaries, ambulatory care claims, inpatient claims, and prescriptions dispensed at pharmacies. All medical records in the claims data includes the diagnosis [International Classification of Diseases, Ninth Edition, Clinical Modification (ICD9-CM) diagnosis codes] as well as the details of drugs given and procedures undertaken (e.g., date of prescription/procedure, days of supply, and National Health Insurance codes (NHICs) for all drugs and procedures covered by the program). Data in the Cause of Death Database are collected from official death certificates, data recorded on the death certificates include date of birth, sex, date of death, and cause of death. These databases can be linked with Personal identification numbers (PINs) to provide patient information such as demographics, clinical details, and information regarding cause of death.

\section{Study design and cohort identification}

This study implemented a retrospective cohort design. The target study population were recruited from the National Health Insurance Database between 2001 and 2015. Patients who received Catheter-directed thrombolytic therapy (CDT) or surgical embolectomy (included bypass) for the first time to treat Acute limb ischemia (ALI) were included (eTable 1). The index date was defined the date of hospitalization. Patients who were under 18 years of age, had trauma related diagnoses, missing sex variables, and Length of stays (LOS) over 180 days were excluded. The present study was exempt from Institutional Review Board assessment. The Strengthening the Reporting of Observational Studies in Epidemiology checklist for cohort studies was used to write this manuscript [3].

\section{Outcomes and covariates}

The primary outcome was defined as all-cause in-hospital mortality and the secondary outcome was defined as the risk of limb amputation (eTable 1) during the same period of hospital stay. Patient characteristics investigated in this study included age, sex, comorbidities, and co-medications. Baseline data regarding comorbidities and co-medications were gathered from a one-year look-back period prior to the index date. Detailed definitions of the comorbidities and co-medications are shown in eTables 2 and 3 .

\section{Statistical analysis}

The continuous variables were described using means and standard deviations and categorical variables were described using numbers and proportions. The Rate ratios (RR) for inhospital mortality and amputation risk were estimated using Generalized linear models (GLM) with Poisson assumption. In order to reduce the effects of the confounding variables, we used a Propensity score (PS) matching method to adjust for confounding factors. The PS was derived from a multivariable logistic regression and the covariates included comorbidities and co-medications. Procedure timing, which defined as difference between date of procedure and date of hospitalization, are also analyzed as confounding factors. Detailed definitions regarding comorbidities and co-medications are presented in eTables 2 and 3. Patients who received embolectomies (including bypass procedures) were matched to patients who received CDT in a 1:1 ratio. All statistical analyses were done using SAS 9.4 version software (SAS Institute, Cary, NC).

\section{Results}

The study enrolled patients admitted to hospital with ALI between 2001 and 2015 and received either CDT $(n=905)$ or surgical intervention $(n=4559)$. Patients in the CDT group were older and had a higher proportion of comorbidities compared to patients in the surgical intervention group. After propensity score matching, the two study groups were well balanced $(\mathrm{SMD}<0.1)$ (Table 1$)$.

The rate ratios of in-hospital mortality and amputation risk in patients with ALI are summarized in Table 2. There were no significant differences in mortality risk between CDT and surgical intervention $(9.5 \%$ vs. $10.68 \%$ adjusted rate ratio $(95 \% \mathrm{CI})$ : regression 1.0 [0.79-1.27], PS matching 0.92 [0.69-1.23]). The risk of amputation was also comparable between the two groups. (13.59\% vs. $14.81 \%$ adjusted rate ratio $(95 \% \mathrm{CI})$ : regression 0.84 [0.68-1.02], PS matching 0.92 [0.72-1.17]).

A multiple regression analysis for risk factor evaluation was performed (Table 3$)$. In our study, age $(p<0.001)$ and liver disease $(p=0.01)$ were associated with higher mortality 
Table 1 Baseline characteristics of study population

\begin{tabular}{|c|c|c|c|c|c|c|c|c|c|c|}
\hline \multirow[t]{3}{*}{ Variable } & \multicolumn{5}{|c|}{ Full cohort } & \multicolumn{5}{|c|}{ Matched cohort } \\
\hline & \multicolumn{2}{|l|}{$\mathrm{CDT}$} & \multicolumn{2}{|c|}{$\begin{array}{l}\text { Embolectomy } \\
\text { (included bypass) }\end{array}$} & \multirow[t]{2}{*}{$\mathrm{SMD}^{*}$} & \multicolumn{2}{|l|}{$\mathrm{CDT}$} & \multicolumn{2}{|c|}{$\begin{array}{l}\text { Embolectomy } \\
\text { (included bypass) }\end{array}$} & \multirow[t]{2}{*}{ SMD } \\
\hline & $\mathrm{n}$ & $\%(\mathrm{SD})$ & $\mathrm{n}$ & $\%(\mathrm{SD})$ & & $\mathrm{n}$ & $\%(\mathrm{SD})$ & $\mathrm{n}$ & $\%(\mathrm{SD})$ & \\
\hline Total & 905 & 100.0 & 4559 & 100.0 & & 904 & 100.0 & 904 & 100.0 & \\
\hline \multicolumn{11}{|l|}{ Demographics } \\
\hline Age, mean (SD) & 71.3 & 13.0 & 69.9 & 13.4 & -0.10 & 71.2 & 13 & 70.7 & 12.5 & -0.04 \\
\hline Sex, n, \% & & & & & 0.21 & & & & & 0.02 \\
\hline Female & 387 & 42.8 & 1494 & 32.8 & & 386 & 43 & 376 & 42 & \\
\hline Male & 518 & 57.2 & 3065 & 67.2 & & 518 & 57.3 & 528 & 58.4 & \\
\hline $\begin{array}{l}\text { Procedure timing after hospitali- } \\
\text { zation, mean (SD) }\end{array}$ & 1.31 & 1.2 & 1.62 & 1.4 & -0.24 & 1.28 & 1.2 & 1.32 & 1.3 & -0.09 \\
\hline \multicolumn{11}{|l|}{ Comorbidities, n, \% } \\
\hline Diabetes mellitus & 558 & 61.7 & 2067 & 45.3 & -0.33 & 557 & 61.6 & 551 & 61 & -0.01 \\
\hline Liver diseases & 70 & 7.7 & 358 & 7.9 & 0.00 & 70 & 7.7 & 59 & 6.5 & -0.05 \\
\hline Malignancy & 151 & 16.7 & 577 & 12.7 & -0.11 & 151 & 16.7 & 146 & 16.2 & -0.01 \\
\hline Acute myocardial infarction & 73 & 8.1 & 192 & 4.2 & -0.16 & 73 & 8.1 & 74 & 8.2 & 0.00 \\
\hline Heart failure & 191 & 21.1 & 891 & 19.5 & -0.04 & 191 & 21.1 & 212 & 23.5 & 0.06 \\
\hline Stroke & 240 & 26.5 & 1184 & 26 & -0.01 & 239 & 26.4 & 235 & 26 & -0.01 \\
\hline Ulcer disease & 181 & 20 & 875 & 19.2 & -0.02 & 181 & 20 & 167 & 18.5 & -0.04 \\
\hline PAD & 484 & 53.5 & 2264 & 49.7 & -0.08 & 484 & 53.5 & 500 & 55.3 & 0.04 \\
\hline Atrial fibrillation & 110 & 12.2 & 641 & 14.1 & 0.06 & 110 & 12.2 & 120 & 13.3 & 0.03 \\
\hline Hypertension & 667 & 73.7 & 3066 & 67.3 & -0.14 & 666 & 73.7 & 646 & 71.5 & -0.05 \\
\hline Hyperlipidemia & 262 & 29 & 1208 & 26.5 & -0.05 & 262 & 29 & 258 & 28.5 & -0.01 \\
\hline CVD & 379 & 41.9 & 1718 & 37.7 & -0.09 & 379 & 41.9 & 388 & 42.9 & 0.02 \\
\hline CKD/ESRD & 41 & 4.5 & 138 & 3 & -0.08 & 40 & 4.4 & 28 & 3.1 & -0.07 \\
\hline \multicolumn{11}{|l|}{ Concomitant drug use, $\mathrm{n}, \%$} \\
\hline Anticoagulant & 745 & 82.3 & 3920 & 86.0 & 0.1 & 744 & 82.3 & 760 & 84.1 & 0.05 \\
\hline \multicolumn{11}{|l|}{ History of medication use, $n, \%$} \\
\hline Antiplatelets & 731 & 80.8 & 3364 & 73.8 & -0.17 & 730 & 80.8 & 735 & 81.3 & 0.01 \\
\hline Antithrombotic agents & 338 & 37.3 & 1437 & 31.5 & -0.12 & 337 & 37.3 & 330 & 36.5 & -0.02 \\
\hline RAAS inhibitors & 514 & 56.8 & 2518 & 55.2 & -0.03 & 514 & 56.9 & 495 & 54.8 & -0.04 \\
\hline Beta-blocker agents & 433 & 47.8 & 2102 & 46.1 & -0.03 & 432 & 47.8 & 444 & 49.1 & 0.03 \\
\hline $\mathrm{CCBs}$ & 528 & 58.3 & 2680 & 58.8 & 0.01 & 528 & 58.4 & 499 & 55.2 & -0.06 \\
\hline Diuretics & 372 & 41.1 & 2030 & 44.5 & 0.07 & 371 & 41 & 358 & 39.6 & -0.03 \\
\hline Statins & 309 & 34.1 & 1282 & 28.1 & -0.13 & 308 & 34.1 & 306 & 33.8 & 0.00 \\
\hline NSAIDs & 593 & 65.5 & 3122 & 68.5 & -0.04 & 593 & 65.6 & 585 & 64.7 & 0.01 \\
\hline Antidiabetics & 545 & 60.2 & 1984 & 43.5 & 0.06 & 544 & 60.2 & 541 & 59.8 & -0.02 \\
\hline
\end{tabular}

*SMD standardized mean difference

risks. Heart failure $(p=0.03)$ and chronic or end-stage renal disease $(p=0.03)$ were associated with higher amputation risks. Previous antithrombotic agent use $(p=0.03)$ was associated with a reduced risk of amputation. Gender, diabetes, hypertension, existing peripheral artery disease, stroke, atrial fibrillation, coronary heart disease, concomitant medication use, and procedure timing had no association with in-hospital mortality or amputation risk.

\section{Discussion}

This study is the first populational-based cohort study to investigate the outcomes of ALI in Taiwan. Our results show the following: (1) There were no significant differences between surgical intervention and CDT in regards to mortality and amputation risk, (2) older age and liver disease were associated with higher mortality risks, (3) heart failure and chronic kidney disease/end-stage renal disease were associated higher amputation risks, (4) concomitant 
Table 2 Rate ratio of mortality and amputation risk in patients with acute limb ischemia

\begin{tabular}{|c|c|c|c|c|c|}
\hline \multirow[t]{3}{*}{ Treatment } & \multirow[t]{3}{*}{ Case } & \multirow{3}{*}{$\begin{array}{l}\text { CIR* (per } 1000 \\
\text { persons-days) }\end{array}$} & \multicolumn{3}{|c|}{ Rate ratio $(95 \% \mathrm{CI})$} \\
\hline & & & \multirow[t]{2}{*}{ Unadjusted } & \multicolumn{2}{|l|}{ Adjusted } \\
\hline & & & & Regression & PS matching \\
\hline \multicolumn{6}{|l|}{ Outcome: inhospital mortality } \\
\hline CDT & 86 & 4.6 & 1.00 & 1.00 & 1.00 \\
\hline Embolectomy (included bypass) & 487 & 4.4 & $0.90(0.72-1.13)$ & $1.00(0.79-1.27)$ & $0.92(0.69-1.23)$ \\
\hline \multicolumn{6}{|l|}{ Outcome: amputation } \\
\hline CDT & 123 & 6.6 & 1.00 & 1.00 & 1.00 \\
\hline Embolectomy (included bypass) & 675 & 6.1 & $0.80(0.70-1.02)$ & $0.84(0.68-1.02)$ & $0.92(0.72-1.17)$ \\
\hline
\end{tabular}

*Cummulative incidence rate

Table 3 Multiple regression analysis for in-hospital mortality and amputation risk

\begin{tabular}{|c|c|c|c|c|c|c|}
\hline \multirow[t]{2}{*}{ Variable } & \multicolumn{3}{|c|}{ Outcome: In-hospital mortality } & \multicolumn{3}{|c|}{ Outcome: Amputation } \\
\hline & Estimates & SE & $P$ value & Estimates & SE & $P$ value \\
\hline \multicolumn{7}{|l|}{ Treatment } \\
\hline Embolectomy (included bypass) & 0.12 & 0.15 & 0.43 & -0.07 & 0.12 & 0.60 \\
\hline CDT & 0.00 & - & - & 0.00 & - & - \\
\hline \multicolumn{7}{|l|}{ Demographics } \\
\hline Age & 0.03 & 0.01 & $<.0001$ & -0.01 & 0.01 & 0.22 \\
\hline \multicolumn{7}{|l|}{ Gender } \\
\hline Male & -0.29 & 0.15 & 0.06 & 0.13 & 0.13 & 0.31 \\
\hline Female & 0.00 & - & - & 0.00 & - & - \\
\hline Procedure timing & 0.25 & 0.19 & 0.24 & -0.40 & 0.28 & 0.08 \\
\hline \multicolumn{7}{|l|}{ Comorbidities } \\
\hline Diabetes mellitus & -0.61 & 0.29 & 0.05 & 0.53 & 0.28 & 0.06 \\
\hline Liver diseases & 0.58 & 0.24 & 0.01 & -0.20 & 0.26 & 0.44 \\
\hline Malignancy & 0.14 & 0.19 & 0.47 & -0.14 & 0.18 & 0.45 \\
\hline Acute myocardial infarction & 0.02 & 0.29 & 0.95 & -0.01 & 0.29 & 0.97 \\
\hline Heart failure & 0.26 & 0.21 & 0.21 & 0.40 & 0.18 & 0.03 \\
\hline Stroke & -0.30 & 0.18 & 0.10 & -0.05 & 0.15 & 0.74 \\
\hline Ulcer disease & 0.23 & 0.18 & 0.20 & 0.00 & 0.16 & 1.00 \\
\hline Peripheral arterial occlusive disease & -0.36 & 0.17 & 0.05 & 0.05 & 0.14 & 0.69 \\
\hline Atrial fibrillation & 0.13 & 0.24 & 0.60 & -0.43 & 0.29 & 0.13 \\
\hline Hypertension & -0.18 & 0.20 & 0.38 & 0.19 & 0.17 & 0.27 \\
\hline Hyperlipidemia & 0.25 & 0.20 & 0.21 & -0.05 & 0.16 & 0.77 \\
\hline CKD/ESRD & 0.03 & 0.39 & 0.94 & 0.59 & 0.27 & 0.03 \\
\hline CVD & -0.02 & 0.19 & 0.93 & -0.24 & 0.16 & 0.14 \\
\hline \multicolumn{7}{|l|}{ Co-medication } \\
\hline Antiplatelets & 0.12 & 0.21 & 0.58 & -0.10 & 0.17 & 0.56 \\
\hline Antithrombotic agents & 0.20 & 0.18 & 0.27 & -0.36 & 0.16 & 0.03 \\
\hline RAAS inhibitors & 0.14 & 0.18 & 0.45 & -0.12 & 0.15 & 0.42 \\
\hline Beta-blocker agents & -0.09 & 0.17 & 0.59 & -0.09 & 0.14 & 0.51 \\
\hline CCBs & -0.14 & 0.18 & 0.43 & -0.16 & 0.14 & 0.27 \\
\hline Diuretics & 0.02 & 0.17 & 0.92 & -0.23 & 0.15 & 0.12 \\
\hline Statins & -0.37 & 0.20 & 0.07 & -0.31 & 0.16 & 0.05 \\
\hline Non-statin lipid lowering agents & -0.53 & 0.36 & 0.13 & 0.23 & 0.21 & 0.28 \\
\hline Antidiabetes & 0.50 & 0.30 & 0.09 & 0.00 & 0.27 & 0.99 \\
\hline NSAIDs & -0.06 & 0.16 & 0.69 & 0.04 & 0.13 & 0.75 \\
\hline
\end{tabular}


antithrombotic agent use during hospitalization was associated with lower amputation risks.

We observed clear differences in treatment preferences based on patient characteristics. Prior to propensity weighting, patients who received surgical interventions were typically younger and had fewer comorbidities (diabetes mellitus, malignancy, previous myocardial infarction, hypertension, etc.). Patients who received CDT were more likely to have been prescribed antiplatelets, anti-thrombotics, and statins, corresponding with the higher prevalence of comorbidities in this group of patients.

There is currently very limited data on ALI outcomes. Although a number of trials comparing surgery and thrombolysis for ALI have been conducted [4, 5], there is significant degree of heterogenicity between those studies and it would be difficult for a conclusion to be made based on those studies. A meta-analysis conducted by the Cochrane Database suggested no significant differences between the two procedures in regards to limb salvage or death at 30 days [6]. However, all five trials included in the review were published before 2000. With advancement of catheter technology, the outcomes reported in those studies may not be as relevant today. In 2013, Ashraf et al. reported lower 30-day mortality and amputation rates with CDT compared to surgical intervention (mortality rates of $5.4 \%$ vs $13.2 \%$ and amputation rates of $6.5 \%$ vs $13.5 \%$ respectively) [7]. However, our study did not find a clear difference between these two parameters. Our study showed a higher prevalence of diabetes during an analysis of patient characteristics. Since the Rutherford category was not reported in our study, the severity of lower limb arterial disease and ischemia could not be evaluated in our study population. Some patients in this study may have had Rutherford III ischemia, which confers a significantly higher mortality and amputation rate.

In our study, age and liver disease were associated with a higher mortality risk. Heart failure and advanced kidney disease were associated with a higher amputation risk. These finding are mostly consistent with what has been reported in the literature in regards to risk factors for both acute and critical limb ischemia [2,8]. However, liver disease has yet to be reported as a risk factor for mortality in limb ischemia. Chronic hepatitis B virus (HBV) and hepatitis C virus $(\mathrm{HCV})$ infections are two major causes of chronic liver diseases and liver cirrhosis [9]. Taiwan is an HBV and HCV endemic country [10]. In our study, $7-8 \%$ of the study population had existing liver disease. Coagulopathy is a common finding in chronic liver disease, particular in the end stage liver disease [11]. Hemorrhagic events are an important risk factor for mortality [8]. The higher prevalence of liver disease in our study population may decrease the significance of this influence.

Duration of the diseases influenced outcomes of CDT has been reported before [12]. Therefore, procedure timing was listed as a confounding factor and adjusted by propensity score matching. Multivariable logistic regression indicated that procedure timing has no association with in-hospital mortality or amputation risk in our study population.

The findings of this study should be interpreted in light of several limitations. This study relied on discharge diagnosis codes to identify ALI events, and as such, inaccurate coding may have been a significant limiting factor in regards to this study's inclusion criteria. In addition, previous studies have suggested a difference in thrombolytic outcomes between patients with embolic and non-embolic ischemia [13]. The NHIRD diagnosis code does not allow for the separate analysis of patients presenting with embolic and non-embolic ischemia. Besides, the information for indication of choosing one treatment modality from another are missing. CDT treatment is usually used for the management of patients who are having more underlying diseases. To reduce effects of age and comorbidities, a propensity score matching method was used to balance both groups. The database also lacks information on the affected vessels for individual patients. Newer endovascular devices, such as mechanical thrombectomies or pharmaco-mechanical thrombectomies, are not included in national health insurance system. Patients with ALI presented with different Rutherford class severities, which in turn, indicated different prognoses [14]. Detailed information on Rutherford class severity is not available in the NHIRD.

In conclusion, ALI remains a morbid condition with high risk of limb loss and death. Both surgical intervention and CDT are effective and feasible procedures for patients with ALI in Taiwan. The revascularization plan should be made carefully based on patient characteristics. Additional clinical data of good quality are needed to define longer term outcomes.

Supplementary Information The online version contains supplementary material available at https://doi.org/10.1007/s11239-021-02532-1.

Acknowledgements We are grateful for the generosity of the Taiwan Bureau of National Health Insurance for giving us access to the National Health Insurance Research Database. We are also grateful to the Health Data Science Center, National Cheng Kung University Hospital for providing administrative and technical support.

Author contributions Dr PKY was responsible for drafting of the manuscript. Dr CCS was responsible for the data analysis. All authors were responsible for the study concept and design, interpretation of the data, preparation, review or approval of the manuscript, revision of intellectual content, and the decision to submit the final manuscript for publication.

Funding This study was funded by National Cheng Kung University Hospital, Grant numbers NCKUH-10709008 and NCKUH-10809001. The funding resource had no role in the design, conduct or analysis of this study or in the decision to submit the manuscript for publication. 
Data availability Data are available from the National Health Insurance Research Database (NHIRD) published by Taiwan National Health Insurance (NHI) Bureau. Due to legal restrictions imposed by the government of Taiwan in relation to the "Personal Information Protection Act", data cannot be made publicly available. Requests for data can be sent as a formal proposal to the NHIRD (http://nhird.nhri.org.tw).

\section{Declarations}

Conflict of interest The authors have nothing to declare with regard to conflict of interest.

Ethical approval This study adhered to the Declaration of Helsinki. This is an observational study. The Human Research and Ethics Committee of National Cheng Kung University Hospital has confirmed than no ethical approval is required.

Open Access This article is licensed under a Creative Commons Attribution 4.0 International License, which permits use, sharing, adaptation, distribution and reproduction in any medium or format, as long as you give appropriate credit to the original author(s) and the source, provide a link to the Creative Commons licence, and indicate if changes were made. The images or other third party material in this article are included in the article's Creative Commons licence, unless indicated otherwise in a credit line to the material. If material is not included in the article's Creative Commons licence and your intended use is not permitted by statutory regulation or exceeds the permitted use, you will need to obtain permission directly from the copyright holder. To view a copy of this licence, visit http://creativecommons.org/licenses/by/4.0/.

\section{References}

1. Norgren L, Hiatt WR, Dormandy JA, Nehler MR, Harris KA, Fowkes FGR (2007) Inter-society consensus for the management of peripheral arterial disease (TASC II). J Vasc Surg 45(1):S5S67. https://doi.org/10.1016/j.jvs.2006.12.037

2. Ouriel K, Veith FJ, Sasahara AA (1996) Thrombolysis or peripheral arterial surgery: phase I results. J Vasc Surg 23(1):64-75. https://doi.org/10.1016/S0741-5214(05)80036-9

3. Erik DGA, Matthias E, Stuart JP, Peter CG, Jan PV (2007) The Strengthening the reporting of observational studies in epidemiology (STROBE) statement: guidelines for reporting observational studies. Lancet 370(9596):1453-1457. https://doi.org/10.1016/ S0140-6736(07)61602-X

4. Ouriel K, Shortell CK, DeWeese JA, Green RM, Francis CW, Azodo MVU, Gutierrez OH, Manzione JV, Cox C, Marder VJ (1994) A comparison of thrombolytic therapy with operative revascularization in the initial treatment of acute peripheral arterial ischemia. J Vasc Surg 19(6):1021-1030. https://doi.org/10. 1016/S0741-5214(94)70214-4

5. Ouriel K, Veith FJ, Sasahara AA (1998) A comparison of recombinant urokinase with vascular surgery as initial treatment for acute arterial occlusion of the legs. N Engl J Med 338(16):11051111. https://doi.org/10.1056/nejm199804163381603

6. Darwood R, Berridge DC, Kessel DO, Robertson I, Forster R (2018) Surgery versus thrombolysis for initial management of acute limb ischaemia. Cochrane Database Syst Rev. https://doi. org/10.1002/14651858.CD002784.pub3

7. Taha AG, Byrne RM, Avgerinos ED, Marone LK, Makaroun MS, Chaer RA (2015) Comparative effectiveness of endovascular versus surgical revascularization for acute lower extremity ischemia. J Vasc Surg 61(1):147-154. https://doi.org/10.1016/j.jvs.2014.06. 109

8. Genovese EA, Chaer RA, Taha AG, Marone LK, Avgerinos E, Makaroun MS, Baril DT (2016) Risk factors for long-term mortality and amputation after open and endovascular treatment of acute limb ischemia. Ann Vasc Surg 30:82-92. https://doi.org/10.1016/j. avsg.2015.10.004

9. Hayashi PH, Di Bisceglie AM (2005) The progression of hepatitis B- and C-infections to chronic liver disease and hepatocellular carcinoma: epidemiology and pathogenesis. Med Clin North Am 89(2):371-389. https://doi.org/10.1016/j.mena.2004.08.014

10. Tsai M-C, Kee K-M, Chen Y-D, Lin L-C, Tsai L-S, Chen H-H, Lu S-N (2007) Excess mortality of hepatocellular carcinoma and morbidity of liver cirrhosis and hepatitis in HCV-endemic areas in an HBV-endemic country: geographic variations among 502 villages in southern Taiwan. J Gastroenterol Hepatol 22(1):92-98. https://doi.org/10.1111/j.1440-1746.2006.04489.x

11. Tripodi A, Mannucci PM (2011) The coagulopathy of chronic liver disease. N Engl J Med 365(2):147-156. https://doi.org/10. 1056/NEJMra1011170

12. Poredos P, Keber D, Videcnik V (1989) Late results of local thrombolytic treatment of peripheral arterial occlusions. Angiology 40(11):941-947. https://doi.org/10.1177/000331978904001 101

13. Lurie F, Vaidya V, Comerota AJ (2015) Clinical outcomes and cost-effectiveness of initial treatment strategies for nonembolic acute limb ischemia in real-life clinical settings. J Vasc Surg 61(1):138-146. https://doi.org/10.1016/j.jvs.2014.07.086

14. Wang JC, Kim AH, Kashyap VS (2016) Open surgical or endovascular revascularization for acute limb ischemia. J Vasc Surg 63(1):270-278. https://doi.org/10.1016/j.jvs.2015.09.055

Publisher's Note Springer Nature remains neutral with regard to jurisdictional claims in published maps and institutional affiliations. 